\title{
Adsorption of Nitrogen and Phosphorus in Water by Eggshell Modified with $\mathrm{FeCl}_{3}$
}

\author{
Hongcui $\mathrm{Li}^{1}$, Yurong $\mathrm{Li}^{1}$, Feifei Yan ${ }^{1}$ and Xiangzheng Yin ${ }^{1}$ \\ ${ }^{1}$ Qilu Institute of Technology, Jinan City, Shandong Province, China
}

\begin{abstract}
As a kind of domestic waste, eggshell has developed pore structure and good adsorption capacity. The material was selected as adsorbent to study the adsorption of total nitrogen and total phosphorus in water. After being modified by ferric chloride, its adsorption effect is greatly enhanced. The adsorption of nitrogen and phosphorus in water by eggshell modified by ferric chloride was studied under different conditions. The experimental results show that the adsorption capacity after modification is $15 \% \sim 40 \%$ higher than that before modification. The results of orthogonal experiment show that under the following conditions: $\mathrm{pH}$ value was 5.00 , dosage was $0.050 \mathrm{~g}$, time was $65 \mathrm{~min}$, the maximum adsorption capacity of total phosphorus was 45.34 $\mathrm{mg} / \mathrm{g}$; under the following conditions: $\mathrm{pH}$ value was 4.50 , dosage was $0.100 \mathrm{~g}$, time was $60 \mathrm{~min}$, the maximum adsorption capacity of total nitrogen was $79.91 \mathrm{mg} / \mathrm{g}$.
\end{abstract}

environment.

\section{Introduction}

With the continuous development of society and economy, and the extensive use of chemical fertilizers and pesticides, substances rich in nitrogen and phosphorus are constantly pouring into lakes, rivers, oceans and other water bodies, resulting in the rapid propagation of algae and plankton, the consumption of dissolved oxygen in water, and the death of aquatic organisms due to hypoxia, which makes water pollution increasingly serious and the problem of water eutrophication prominent ${ }^{[1,2]}$. The key to reduce eutrophication is to remove nitrogen and phosphorus from water.

At present, biological method, precipitation method, adsorption method and ion exchange method are commonly used to remove nitrogen and phosphorus at home and abroad. Using adsorption method to remove total nitrogen (TN) and total phosphorus (TP) in water is the current research hotspot ${ }^{[3-4]}$. Adsorption method has the advantages of simple process, various types and wide application range, which has attracted much attention in wastewater treatment ${ }^{[5]}$. Eggshell has its own utilization value. As a kind of domestic waste, eggshell is rich in resources and low in cost. Its main component is calcium carbonate, with developed pore structure and good adsorption capacity ${ }^{[6-9]}$. According to the pre-experiment, the adsorption capacity of unmodified eggshell is limited. In order to improve the adsorption efficiency of eggshell, it is modified with ferric chloride, because ferric chloride has an important application in coagulation and sedimentation of water treatment ${ }^{[10]}$. Taking eggshell as a kind of resource, turning waste into treasure and developing comprehensive utilization can achieve the coordinated development of economy, society and

\section{Materials And Methods}

\subsection{Experimental Instruments and Materials}

XFH-75CA vertical high-pressure steam sterilizer (Shanghai Precision Instrument Co., Ltd.); SW-CJ-1D single super clean workbench (Suzhou purification equipment Co., Ltd.); SHZ-82A thermostatic oscillator (Changzhou Guohua Electric Co., Ltd.); 722 type visible spectrophotometer (Shanghai Precision Instrument Co., Ltd.); 752 type ultraviolet visible spectrophotometer (Shanghai Yuan Analytical Instrument Co., Ltd.).

Domestic sewage is from a municipal sewage treatment plant. The main pollutant indexes are TN and TP.

\subsection{Experimental Method}

2.2.1 Eggshell modified by ferric chloride. Eggshell is a kind of porous material, the main component is $\mathrm{CaCO}_{3}$, which has developed pore structure and good adsorption performance. The porous structure can be used to adsorb nitrogen and phosphorus in wastewater. The modified eggshell, with $\mathrm{Fe}^{3+}$ on its surface, hydrolyzes strongly in water and polymerizes at the same time to form polynuclear hydroxyl complex to adsorb phosphorus in water. After the eggshell was modified, its pores increased and its ability of nitrogen adsorption increased. The eggshell was modified by $\mathrm{FeCl}_{3}$ and used to treat wastewater containing nitrogen and phosphorus. The effect of different adsorption conditions on the adsorption of nitrogen and phosphorus was discussed. Ammonium 
molybdate spectrophotometry was used to measure TP and potassium persulfate digestion was used to measure $\mathrm{TN}^{[11]}$. The collected eggshells were soaked and cleaned with deionized water to remove the inner eggshell membrane, dried at $60{ }^{\circ} \mathrm{C}$ in the blast drying oven, crushed and screened for standby ${ }^{[12]}$.

At room temperature, take $10.000 \mathrm{~g}$ eggshell powder, put it into a $500 \mathrm{~mL}$ beaker, add $100 \mathrm{~mL} 0.5 \mathrm{~mol} / \mathrm{L} \mathrm{FeCl}_{3}$ solution, stir it on a magnetic stirrer for $24 \mathrm{~h}$, filter it, wash it with deionized water until it is colorless, then dry it at $60{ }^{\circ} \mathrm{C}$ in a blast drying oven, crush and screen it for standby.

2.2.2 Single factor adsorption experiment. Single factor adsorption experiments were conducted to explore the effects of reaction time, adsorbent dosage and $\mathrm{pH}$ on the removal rate of $\mathrm{TP}$ and $\mathrm{TN}$ in domestic sewage. The experimental process is as follows: take $100 \mathrm{~mL}$ of domestic sewage, add it into $\mathrm{n} 250 \mathrm{~mL}$ conical flasks, add the modified eggshell, adjust the reaction time, dosage, $\mathrm{pH}$ value, and determine the concentration of TP and TN before and after the reaction under different single factor conditions. The removal rate was calculated and the optimal reaction time, dosage and $\mathrm{pH}$ value were determined.

\subsubsection{Orthogonal Experiment. In the actual sewage}

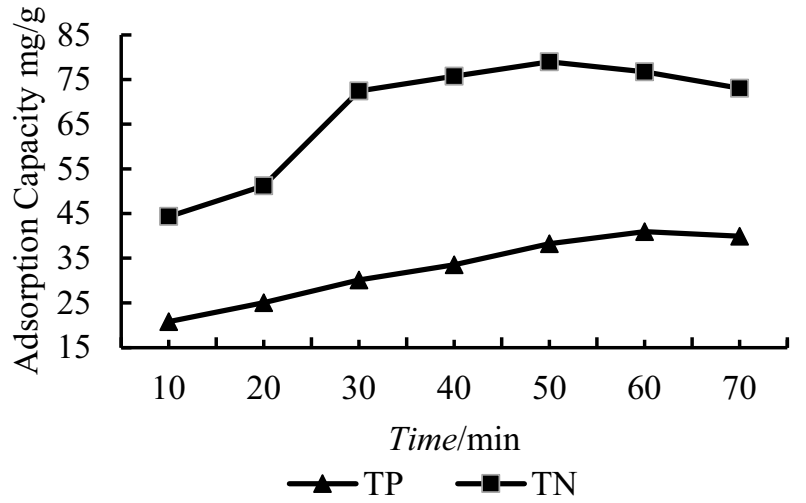

(a)Time treatment process, not all factors play a role alone, but a variety of factors play a role together. Therefore, $\mathrm{L}_{9}\left(3^{4}\right)$ orthogonal experiment is designed with reaction time (A), dosage $(\mathrm{B})$ and $\mathrm{pH}(\mathrm{C})$ as the investigation factors ${ }^{[13]}$. The factor level table is shown in Table 1, and the determination method is the same as the adsorption experiment.

Table 1. Table of orthogonal experimental factors.

\begin{tabular}{ccccc}
\hline \multirow{2}{*}{ Index } & Factor & $\begin{array}{c}\text { Time } \\
(\mathrm{min})\end{array}$ & $\begin{array}{c}\text { Dosage } \\
(\mathrm{g})\end{array}$ & $\mathrm{pH}$ \\
\cline { 3 - 5 } & 1 & $\mathrm{~A}$ & $\mathrm{~B}$ & $\mathrm{C}$ \\
\hline \multirow{3}{*}{$\mathrm{TP}$} & 2 & 65 & 0.05 & 4.5 \\
& 3 & 65 & 0.10 & 5.0 \\
& 1 & 50 & 0.15 & 5.5 \\
$\mathrm{TN}$ & 2 & 55 & 0.05 & 4.5 \\
& 3 & 60 & 0.10 & 5.0 \\
& 1 & & & \\
\hline
\end{tabular}

\section{Results and Discussion}

\subsection{Single Factor Experiment Results}

The results of single factor experiment are shown in Figure 1. When the reaction reaches equilibrium, the best reaction time of modified eggshell of TP, TN treatment is $60 \mathrm{~min}, 50 \mathrm{~min}$, the best dosage is $0.100 \mathrm{~g}, 0.100 \mathrm{~g}$, and the best reaction $\mathrm{pH}$ is $5.00,5.00^{[14]}$.

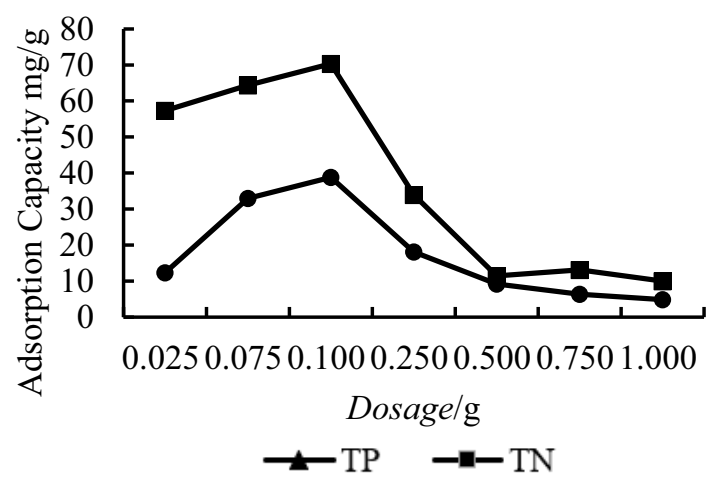

(b)Dosage

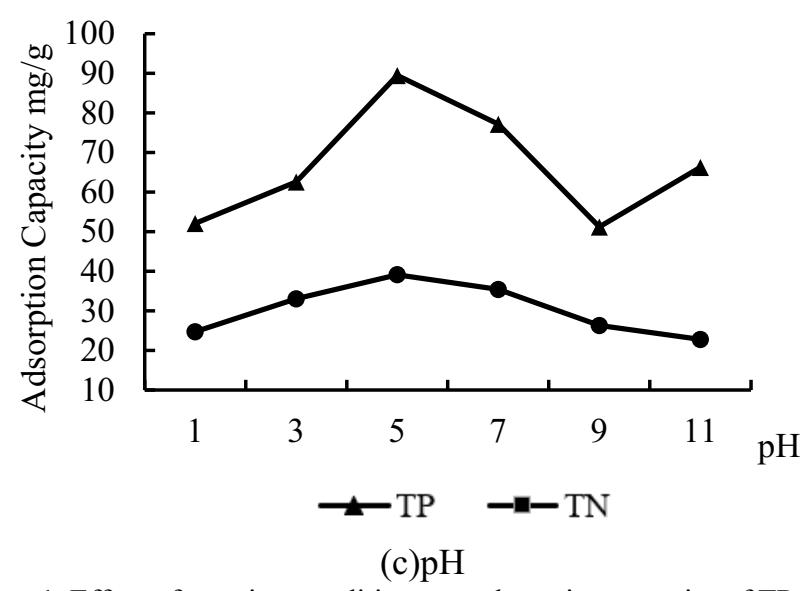

Figure 1. Effect of reaction conditions on adsorption capacity of TP and TN. 


\subsection{Orthogonal Experiment Results and Discussion}

The reaction time, dosage and $\mathrm{pH}$ were selected as the factors, and the adsorption capacity of different pollutants was taken as the index. The orthogonal experiment was designed according to $L_{9}\left(3^{4}\right)$. Orthogonal experiment design and results in Table 2, visual analysis in Table 3 and variance analysis in Table 4.

Table 2. Orthogonal experimental design and results.

\begin{tabular}{|c|c|c|c|c|c|c|}
\hline \multirow{2}{*}{$\begin{array}{l}\text { Group } \\
\text { number }\end{array}$} & \multirow{2}{*}{ A } & \multirow{2}{*}{ B } & \multirow{2}{*}{ C } & \multirow{2}{*}{$\begin{array}{c}\mathrm{D} \\
\text { (blank) }\end{array}$} & \multicolumn{2}{|c|}{ Adsorption Capacity (mg/g) } \\
\hline & & & & & $\mathrm{TP}$ & $\mathrm{TN}$ \\
\hline 1 & 1 & 1 & 1 & 1 & 41.62 & 71.38 \\
\hline 2 & 1 & 2 & 2 & 2 & 36.57 & 78.08 \\
\hline 3 & 1 & 3 & 3 & 3 & 29.05 & 63.01 \\
\hline 4 & 2 & 1 & 2 & 3 & 44.56 & 61.35 \\
\hline 5 & 2 & 2 & 3 & 1 & 35.79 & 72.15 \\
\hline 6 & 2 & 3 & 1 & 2 & 30.42 & 65.17 \\
\hline 7 & 3 & 1 & 2 & 2 & 45.34 & 65.91 \\
\hline 8 & 3 & 2 & 1 & 3 & 37.55 & 79.91 \\
\hline 9 & 3 & 3 & 3 & 1 & 33.27 & 63.29 \\
\hline & & lent & & & $\mathrm{A}_{3} \mathrm{~B}_{1} \mathrm{C}_{2}$ & $\mathrm{~A}_{3} \mathrm{~B}_{2} \mathrm{C}_{1}$ \\
\hline
\end{tabular}

Table 3. Visual analysis table.

\begin{tabular}{|c|c|c|c|c|c|}
\hline Category & Index & $A$ & $B$ & $C$ & $D$ (blank) \\
\hline \multirow{5}{*}{$\mathrm{TP}$} & $K_{1}$ & 35.75 & 43.84 & 36.53 & 36.89 \\
\hline & $K_{2}$ & 36.92 & 36.64 & 42.16 & 37.44 \\
\hline & $K_{3}$ & 38.72 & 30.91 & 32.70 & 37.05 \\
\hline & $R$ & 2.97 & 12.93 & 9.46 & 0.55 \\
\hline & Factor ranking & \multicolumn{4}{|c|}{$B, A, C$} \\
\hline \multirow{4}{*}{$\mathrm{TN}$} & $K_{1}$ & 70.82 & 66.21 & 72.15 & 68.94 \\
\hline & $K_{2}$ & 66.22 & 76.71 & 68.45 & 69.72 \\
\hline & $K_{3}$ & 69.70 & 63.82 & 66.15 & 68.09 \\
\hline & $R$ & 4.60 & 12.89 & 6 & 1.63 \\
\hline
\end{tabular}

Note: $K_{1}, K_{2}, K_{3}$ represent the mean value of experimental results, and $R$ represents the range.

Table 4. Analysis of varianc.

\begin{tabular}{ccccccc}
\hline & Factors & $S$ & Freedom & $F$ & Critical value of $F$ & $\alpha$ \\
\hline \multirow{2}{*}{$\mathrm{TP}$} & Time & 0.0196 & 2 & 4.9865 & 3.00 & $*$ \\
& Dosage & 0.0295 & 2 & 0.7497 & 3.00 & \\
& $p H$ & 0.0279 & 2 & 7.1041 & 3.00 & $*$ \\
\multirow{4}{*}{$\mathrm{TN}$} & Time & 0.0022 & 2 & 0.0462 & 3.00 & \\
& Dosage & 0.0198 & 2 & 0.4160 & 3.00 & \\
& $p H$ & 0.0098 & 2 & 0.2050 & 3.00 & \\
\hline \multicolumn{4}{c}{} \\
& $F_{0.25}(2,2)=3.00$ & $F_{0.10}(2,2)=9.00$ & $F_{0.05}(2,2)=19.00$ & $F_{0.01}(2,2)=99.00$ &
\end{tabular}

Note: * indicates that this factor has significant influence.

According to the results of orthogonal experiment:

(1) In the orthogonal experiment with TP adsorption capacity as the index, according to the experimental results and the intuitive analysis table, the best combination of experimental conditions is $\mathrm{A}_{3} \mathrm{~B}_{1} \mathrm{C}_{2}$, that is, the reaction time is $65 \mathrm{~min}$, the dosage is $0.05 \mathrm{~g}$, and the reaction $\mathrm{pH}$ value is $5.0 \mathrm{~g}$. The order of influence of three factors on TP adsorption capacity is dosage, reaction time, and $\mathrm{pH}$. The analysis of variance showed that the effect of reaction time and $\mathrm{pH}$ on $\mathrm{TP}$ adsorption capacity of modified eggshell was significant at the level of $\alpha=0.25$, and the significance of $\mathrm{pH}$ was greater than that of reaction time.

(2) In the orthogonal experiment with TN removal capacity as the index, according to the experimental results and visual analysis table, the best combination of experimental conditions is $\mathrm{A}_{3} \mathrm{~B}_{2} \mathrm{C}_{1}$, that is, reaction time is $60 \mathrm{~min}$, dosage is $0.10 \mathrm{~g}$, and reaction $\mathrm{pH}$ value is 4.5 . The order of influence of three factors on removal rate is dosage, $\mathrm{pH}$, and reaction time. The analysis of variance 
showed that the three factors had no significant effect on the adsorption capacity of $\mathrm{TN}$, which indicated that the three factors had no significant difference on the adsorption capacity of $\mathrm{TN}$, and they had a synergistic effect on the adsorption capacity of TN.

(3) To the modified eggshell, the adsorption rate of TN $>$ The adsorption rate of TP. The results show that the modified eggshell adsorption of pollutants is mainly pore adsorption and cation adsorption. The modified iron ion is easy to adsorb nitrate and phosphate in anionic state, which can promote the absorption of TP and TN.

\section{Conclusion}

Eggshell, as a kind of domestic waste, has high adsorption activity. This material was selected as adsorbent in the experiment, and modified with ferric chloride to increase its adsorption activity. Taking TN and TP as experimental objects, the adsorption of TN and TP in domestic sewage by modified eggshell is higher than that of unmodified eggshell, which provides new research value for the secondary utilization of eggshell and domestic sewage treatment. However, the adsorption capacity of TP is not high, and the final disposal of modified eggshell needs further research and improvement.

\section{Reference}

1. Kong J, Zhou Z F, Dan Y S, Jiang Y, Li S H. (2021) Eutrophication evaluation of Pingzhai reservoir based on fractal interpolation model [J]. Journal of irrigation and drainage, 40 (01): 123-130.

2. Teng Q M, Sun Y J, Shen Y Y, Zhang D N, Xu G P, Zhou L W, Zhang Z F, Huang K C, He W, He C X. (2021) Response of growth and phenotypic plasticity characteristics of Eichhornia crassipes to different eutrophic water bodies in Karst wetland [J]. Lake Science, 33 (01): 123-137.

3. Ding J D. (2019) Study on the effect of Modified Attapulgite on eutrophic water and sediment coverage [D]. Hangzhou Normal University.

4. Cheng M Q, Cheng M Y, Wang Z F, Zhang Y J Zhao $Z$ M. (2021) Removal efficiency of nitrogen and phosphorus in domestic sewage by nano zero valent iron loaded on blast furnace alkali slag [J / OL]. Journal of Environmental Engineering: 1-13.

5. Zhou Y H. (2018) Comparative study on adsorption effect of fly ash and carbonized straw on nitrogen and phosphorus in rural domestic sewage $[\mathrm{J}]$. Pollution control technology, 31 (03): 30-34.

6. Tian X, Zhou W J, Zheng W G, Gao Y H, Cao H Y. (2020) Adsorption and desorption of nitrogen and phosphorus from garden waste biochar at different carbonization time $[\mathrm{J}]$. Forestry and Environmental Sciences, 36 (05): 41-47.

7. Li H R, Wu L P, Wen K J, Wang T, Ma X, Li M H. (2020) Adsorption characteristics of phosphorus in water by potassium permanganate modified eggshell [J]. Journal of Tianjin urban construction university,
26 (03): 208-212.

8. Gao X W. (2019) Study on phosphorus removal characteristics of three adsorption materials chemically enhanced by $\mathrm{FeCl}_{3}[\mathrm{D}]$. Shenyang Jianzhu University.

9. Zhou Y H. (2018) Comparative study on adsorption effect of fly ash and carbonized straw on nitrogen and phosphorus in rural domestic $\mathrm{s} \mathrm{FeCl}_{3}$ wage [J]. Pollution control technology, 31 (03): 30-34

10. Li Y. (2017) Study on iron salt modified sludge straw based activated carbon and its $\mathrm{H} 2 \mathrm{~S}$ removal performance [D]. Huazhong University of science and technology.

11. Gu D J, Liu Q. (2020) Determination of total nitrogen in water by Ultraviolet Spectrophotometry with alkaline potassium persulfate digestion [J]. Shandong chemical industry, 49 (11): 103-105.

12. Li X L, Xin L, Zhang R Z, Wei Y S. (2020) Experimental study on adsorption performance of modified eggshell for $\mathrm{Ni}$ ( II ) in wastewater [J]. Hydrometallurgy, 39 (03): 250-255.

13. Jia C Y, Li W, Zhang C H, Wang Y H, Jiang Y, Chen J, Zhao F P, Yang R P. (2016) Optimization of extraction process of compound Baihuang xierezhili tablets based on multi index weight analysis and orthogonal design $[\mathrm{J}]$. Chinese herbal medicine, 47 (06): 917-922.

14. Wang Z, Jiang N, Wang Y, et al. (2012) Effect of sulfate on adsorption capacity and kinetics of polycarboxylate superplasticizer [J]. Acta silicate Sinica, 40 (11): 1586-1591. 